\title{
COMPRENDER Y ESCRIBIR LO DIFÍCIL. Relatar perdiéndose en lo conflictivo de la educación
}

\author{
Eulàlia Collelldemont Pujadas \\ Universitat de Vic - Universitat Central de Catalunya - UVic - UCC, Espanha \\ Anna Gómez Mundó \\ Universitat de Vic - Universitat Central de Catalunya - UVic - UCC, Espanha
}

\begin{abstract}
Resumen
Mediante una revisión de diferentes experiencias de investigación sobre la historia y política de la educación, el artículo propone tomar en cuenta lo difícil, pero no como un reto, ni un obstáculo, sino como parte constituyente tanto de la educación como de la historia. Pensarla, comprenderla, escribirla y enseñarla son procesos inherentes a la pedagogía en los que inevitablemente topamos con la dificultad a no ser que nos tapemos los ojos o desviemos la vista. A pesar de que las costumbres universitarias han litigado para estar en el centro del poder, y se han habituado a unos discursos vehementes, la cuestión es que tanto la universidad como sus enseñanzas viven en sus márgenes. Al tener conciencia de ello, esconderse en las palabras retorcidas ya no es una opción para no afrontar la dificultad de decir lo complejo, lo feo, lo oculto, lo bello y todas aquellas características que el proceso educativo conlleva. Es percatarse que metodología, epistemología, ética, política y conocimiento es un todo, también en la investigación educativa.
\end{abstract}

Palabras clave: Epistemología; Procesos de investigación; Historia de la Educación; Complejidades; Escritura.

\begin{abstract}
By reviewing several experiences on historical and political education researches, this paper proposes to take into account what's "difficult". Not as a challenge neither as an obstacle, but as a constitutive part of both history and education. To think about it, to understand it, and to teach it are inherent processes to the pedagogy. And the "difficult" can not be avoided, unless we close our eyes or we deliberately ignore it. Although the academic uses have struggled to be at the core of the power, and are used to the vehement speeches, the fact is that both the universities and their teachings live in their margins. Once consciousness about it is reached, hiding yourself behind distorted words is no longer an option. Although how much "difficult" it might be, what's complex, what's ugly, what's hidden, and what's beautiful too, they need to be taught. We need to be aware that the methodology, the epistemology, the ethics, politics and knowledge, they constitute a whole. And in the educational investigation too.
\end{abstract}

Keywords: Epistemology; Research process; History of Education; Complexities; Writing. 
En un acto de investigación reciente se invitó a un compositor, Lluís Solé, a crear una música que expresara lo que en su memoria era la educación durante el franquismo ${ }^{1}$. Según nos contó músico, convocar a sus memorias fue casi instantáneo, componer a partir de ellas fue lo difícil. Difícil porque apelaba a la necesidad de expresar mediante un registro sonoro la hostilidad, el feísmo, la banalidad y el silencio, nociones todas ellas derivadas de un entorno de opresión que transmitían ambientes y estados de ánimo que con los años había desterrado de su vida. Se sumaba a ello el hecho que, en su caso particular, la escolarización se dio en un entorno completamente distinto al habitual, lo que hacía que el recuerdo de su paso por la escuela también difiriera del de la mayoría de chicos de su generación. La suya fue una escolarización en una escuela moderna, las Escuelas Laietana, dirigidas por Josep Pereña, ubicadas en el barrio de Gracia de Barcelona e inauguradas en 1962. Dichas escuelas se caracterizaban por ser humildes, antifranquistas y catalanas; y tenían en su plantilla docente a maestros como el compositor de sardanas Lluís Albert para la enseñanza de música o a Josep Antón Codina como maestro de teatro. Revivir los ecos de una escuela distinta a la experimentada fue complejo, pero la reacción posterior fue de satisfacción. La porosidad de los recuerdos ocultos le habían permitido crear desde el silencio. Su memoria individual fue el contraste que sirvió para resaltar los ecos de lo transmitido históricamente.

En la audición posterior a la composición que se realizó frente a un colectivo de estudiantes, la mayoría de ellos y ellas alejados tanto del período del franquismo como del lenguaje de la música contemporánea, permeó otra dificultad, promovida en esta ocasión por la necesidad de recorrer un viaje a la memoria expresiva de un otro, asomarse a la memoria de otro tiempo y de otros sin anclajes -que hubieran podido dar los conocimientos con el pasado en un marco escolar, familiar o social-, sin recorridos -que hubieran podido aparecer con las conversaciones sobre las experiencias vitales de los protagonistas infantiles de la escuela del franquismo- y casi sin estancias -provocadas estas, por las lecturas, visionados e investigaciones sobre el período-. En un entramado casi en blanco, la recepción solamente podía darse en clave emocional, esperando que la misma diera lugar a ser sensible a lo hostil, lo feo, lo banal y el vacío presente en situaciones del ahora. En esta ocasión, la continuidad entre creación y recepción la daban los poros abiertos por experiencias que, aun cuando siendo distintas, coincidían en el paisaje emocional. Memorias colectivas de conceptos y sensibilidades se aunaron en esta ocasión.

La historia musicada podría haber tenido un final más tenebroso, pues la intención no era pacificar el pasado, sino conocer partes de él. No lo era, tampoco, apropiarse de una memoria colectiva. Menos, buscar consuelo en una historia exenta de complejidades, pues, como recordaba Zweig:

Lo cierto es que estamos cansados de que nos consuele, de que nos intenten convencer de que nuestra vida es sencilla, cuando no lo es.

Un diagnóstico certero, por duro que sea, es mejor que toda esa palabrería blanda como la mantequilla. (Zweig, 2020: p.125) 
El riesgo de caer en esa palabrería blanda de la que habla Zweig es alto, ya que la existencia de varias confusiones ontológicas del conocimiento favorece el pensar que la finalidad del conocimiento es sosegar el espíritu. Una de las confusiones es la de pensar que aquello a aprender es la verdad, otra la de pensar que el acto educativo debe ser placentero y divertido, y otra confusión la dieta de adelgazamiento que ha impulsado la didactización del proceso de enseñanza-aprendizaje y de la divulgación del conocimiento, lo que ha se ha traducido en una simplificación de las ideas acerca de lo que es y cómo es la historia. A todo ello se le ha unido, además, unas lógicas de pensamiento lineales, monocausales y dicotómicas para así dar a entender un mensaje más comprensible y digerible. Parece como si se evitara la emergencia de la complejidad y los puntos de fuga para poder continuar presentando el discurso de la historia como aquel que ha resuelto los problemas acaecidos a lo largo de los tiempos. Sin embargo, ni la educación ni la historia son problemas a resolver, sino realidades a comprender. Por ello no se debe aspirar a dar soluciones, ni rendir cuentas, sino contarlas. Narrarlas. Y otra vez la narración. Porque ciertamente, lo difícil siempre se mezcla con la complejidad, con lo sórdido y lo bello, con lo banal y especial, con lo propio y lo ajeno. La escritura de lo difícil solo será aquella que sea permeable a sus nudos, que sepa plasmar lo superpuesto, adaptándose a aquello que se intuye conocer. Podríamos decir que para ese propósito debemos ayudarnos de una escritura torcida, eso es, una escritura que rompa las rejas de la gramática y de la semántica e invente más allá de lo ya disponible, porque el lenguaje también es música, tacto y cuerpo, y hay palabras que a pesar de sus errores ortográficos y frases que a pesar de sus errores gramaticales -o gracias a ellosconsiguen comunicar algo más que lo que permite la escritura normativa.

Recurrir a la escritura torcida es debido a que lo que queremos plantear es la escritura de lo difícil, y decimos lo difícil porque la educación lo es. En sí misma, la educación es un entramado atravesado de pasiones, intereses, voluntades, pretensiones, resistencias, finalidades compartidas y opuestas. La educación ha sido ideada, contada y vivida des de concepciones diversas - a veces divergentes entre sí- a lo largo de los tiempos. Nuestra época no escapa de esa diversidad de concepciones ni, por lo tanto, de la diversidad de valoraciones y propuestas que sobre ella se han hecho. Y para comprender lo difícil de la historia de la educación debemos admitir la complejidad misma que entraña el acto educativo. Los múltiples elementos que entran en juego cuando alguien enseña y alguien aprende dotan al hecho educativo unas dimensiones que no caben en las demasiado frecuentes descripciones y explicaciones reduccionistas que se dan. Como hemos señalado anteriormente, en el escribir puede que el ánimo divulgativo haya empujado a una presentación simplista de una de las actividades humanas más universales y definitorias del ser humano. Si la concepción educativa que se va adoptando, transmitiendo y reforzando responde a unas pocas ideas simplificadas casi en forma de eslogan publicitario, la tarea de comprender y de contar la educación y su historia no tiene demasiada base para hacerlo des de una perspectiva compleja, crítica y rigurosa. Y así lograr que, utilizando otra expresión de Zweig, que sea "la solidez, no la rigidez" (Zweig, 2020, p.129) lo que caracterice la comprensión y posterior narración. 
Es cierto que hemos empezado escribiendo sobre una experiencia musical, siempre distinta a la narrativa del escribir, pero dado su marco académico, de investigación y de formación en el pensar los episodios oscuros de la historia de la educación, con el subsiguiente encuentro con los no-deseados silencios que hablan a través de los poros, sirvió de ocasión para indagar más detenidamente en este artículo ensayístico sobre "Comprender y escribir lo difícil. Relatar perdiéndose en el conflicto de la educación". Un artículo que abordamos desde la encrucijada de los silencios porosos que hemos ido hallando en nuestro quehacer histórico.

\section{La memoria no se construye desde la universidad, ni individual ni colectivamente, pero puede ser retomada para afianzar una de las otras historias.}

La pregunta que sigue a este planteamiento es la de si sobre si hoy es posible escapar y escribir lo difícil silenciado, si los pequeños rastros que van sucediéndose y dejando sus casi invisibles huellas posibilitan hacer hoy historias de la dificultad. Estos pequeños rastros son a veces despejados por la dedicación de las y los investigadores, otras veces, por la férrea voluntad de la comunidad para preservar unas memorias historiadas orales, unos nombres, unos lugares, unos episodios o unas personas; y, en otras ocasiones, es la reconversión moderna que los hace emerger del subsuelo e incluso podríamos nombrar a la desidia como factor detonante. En cualquier zona encontramos numerosos ejemplos de estos poros que, mediante capas, nos introducen a historias diferentes. Y ciertamente, sus llamadas persisten, a veces como rumores, a veces susurrando, a veces protestando, en otras ocasiones, estando sencillamente allí. Como ejemplo de ello ponemos un letrero en una pared que el paso de los años y la no intervención en el edificio hicieron emerger en el pueblo donde vivimos. El rótulo de "parvulario" de repente podía leerse en la fachada de un edificio que parecía más un bloque de viviendas que un espacio educativo.

El nombre genérico con el que se designaba al centro, "parvulario" nos remitía a un período histórico concreto, el franquismo. La estructura y arquitectura del edificio, funcional y austera, nos remontaba a la década de los 60. El urbanismo circundante previsto en el "Plano General de Ordenación Urbana" de 1961 da cuenta de la proliferación de barrios obreros en pleno desarrollismo económico que ya preveían la creación de bloques de "residencias intensivas" utilizando términos más que urbanos, propios de la agricultura. Pero los anuncios publicitarios daban bien a entender de lo que se trataba en realidad: apartamentos minúsculos, entradas pequeñas, terrazas inexistentes.

En el "Plano General de Ordenación Urbana" de 1961, aparece también la provisión de servicios para la comunidad. La "Ciudad Jardín" incrustada en un pequeño espacio, la determinación de un edificio como especial -que equivaldría a una escuela- son muestras de ello. Pero en la concreción - y tal y como lo manifiesta la comparativa entre el plano de ordenación y una vista aérea actual- sólo se materializó el parvulario cuyo rótulo indicábamos se percibe todavía hoy, una escuela nacional y un mercado comercial que sirvió a la vez de 
centro de formación de personas adultas. Nos parece importante añadir que estos espacios aparecieron como respuesta a las constantes demandas de las comunidades, a sus reivindicaciones dirigidas a paliar los efectos de la desidia en la provisión de servicios sociales, educativos y culturales de las zonas de nueva creación y exclusión constante, a pesar del uso propagandístico que posteriormente se le dio.

No obstante, e incomprensiblemente, llama la atención que en las historias locales e incluso en las historias del barrio, el centro del parvulario no aparece. Existen numerosas imágenes, escritos, noticias de prensa, publicaciones dedicadas a la construcción de los "emblemáticos" pisos de Mateo y Pisos de Can García -quizás por la fuerte impronta en la silueta del pueblo, quizás, porqué fueron un producto de los planes de urbanización, en esta ocasión promovidas por la Delegación Provincial de Barcelona de la Dirección General de la Vivienda que las cualificó de "Viviendas de Renta Limitada Subvencionada" (Casas, P; Crosas, 2007, p.68); existen trabajos de investigación, publicaciones y fotografías de la Escuela pública, entonces escuela nacional, con un primer nombre altamente simbólico de "25 años de paz" (Osa, 2006-2007, p. 78), utilizando el lema de campaña del régimen dictatorial como lavado de imagen de la dictadura.

Pero no hay imágenes de la fachada de este parvulario que aun conociendo el territorio permitan ubicar qué centro del barrio era para saber de su historia ${ }^{2}$. Destaca que, en las fotografías del único parvulario representado, el dependiente del municipio y ubicado en el centro, realizadas todas ellas en el período franquista, no aparece ningún niño o niño, son las autoridades quienes ocupan el protagonismo, lo que redunda en la escasa atención a la infancia en este periodo (Bernal, 2020). El otro, un libro-álbum de autor, de las 310 fotografías seleccionadas solo 18 son sobre espacios y actores educativos. Ninguno de ellos corresponde al parvulario que nos ocupa.

Por todo ello, fue necesario recurrir a la historia oral. Con una entrevista a una antigua maestra del centro supimos que se trataba del parvulario de la Academia Casals, abierto como centro privado en 1945 y que en 1966 estrenaron el centro para los más pequeños en la zona de reciente ubicación. Fue necesario rehuir de los "informantes de calidad" ya consolidados para poder resolver la duda provocada por un rastro. Y es así que, adentrándonos en la intrahistoria, explicada oralmente por una antigua maestra, Josefina Pujadas, y escrita visualmente por Margarita Burgaya i Sunta Pujol en el blog de memoria del centro ahora llamado Casals-Gracia, en motivo de una posterior fusión y reubicación, nos fue posible aproximarnos a la memoria que había detrás de las letras de "Parvulario" incrustadas en la pared. Pero sobretodo nos hizo pensar en las historias de los barrios, centros y personas que no ocuparon un lugar céntrico del discurso, y que todavía hoy no son tema para las historias de la oposición al estado totalitario. Porque éstas son parte de una memoria de resistencia, ubicada en los márgenes a los que desplazaron buena parte de la población. Una historia en la que abundan academias, comunidades hechas a partir de la ayuda entre vecinos -como destacaron los antiguos vecinos de los pisos de Can García, en ocasión de su desmantelamiento en 2017-, actos que, aunque en pequeño, se entrelazan en la historia contextual. Una historia no llamativa, no excepcional (sea lo oficial o lo disidente), pero sí una historia cotidiana y común. Pero, como ya hemos indicado, lo común es difícil por no 
ser estridente, ni en el pasado ni en el hoy. Lo difícil, por su característica de no-aprensivo, escapa de las políticas del texto en el ámbito académico. Como hemos visto, lo difícil, por presentar otras rutas, otras posibilidades huyen del texto hegemónico desde el que se fabricado el consenso, bajo el que se ocultan las disensiones y los múltiples matices de sus defensores.

En definitiva, el consenso no narra el esfuerzo de aquellos colectivos que derivó en la construcción de nuevos espacios educativos que siempre restaron al margen de los noticiarios, como así lo pudimos evidenciar en el estudio centrado en los barrios obreros y de barracas de Barcelona (Collelldemont, Cercós, Padrós, 2019) o de la construcción de escuelas de referencia de la disidencia.

Entonces, en el ejemplo que nos ocupa, podemos pensar que su silenciamiento es comprensible en términos de propaganda de un régimen que declaraba con su voz histriónica su absoluta preocupación para cuidar y potenciar a la ciudadanía. Pero no lo es en términos de la memoria comunitaria ni tampoco de la historia de la educación local. Palabras, construcciones, elementos visuales, trazas en el urbanismo o, en otras ocasiones, recuerdos contados, se empeñan así en proponer otras historias que complementan o incluso desmienten las versiones oficiales de la historia de la educación. Sus registros no los hallaremos en las postales creadas como propaganda de la población o de los centros educativos, no los hallamos en los hitos pasados que recuperan y dan valor (comercial y turístico) a una población y en pocas ocasiones en la historia popular. Una narración que, sin lugar a dudas es común, pero no por ello, normalizada. Ahí aparece una dificultad importante en el hacer historia de la educación, eso es, la dificultad de permitirnos observarla, pensarla, interpretarla y decirla de otra manera a la institucionalizada. Una narración que sin ser amable -como sí lo son los álbumes, y las historias de recuperación para dar valor que esconden y censuran las imágenes de conflicto y, violencias- su rastro sigue estando allí y nos cuenta una narración de dificultades para ser, para estar y para preservar. Cómo indicábamos en el inicio, la memoria no se construye solamente desde la universidad, ni individual ni colectivamente, pero desde la misma si se pueden afianzar una de las otras historias.

\section{Cuando la referencia no impulsa sino ofusca es cuando se requieren otras voces insistentes.}

Nombrar lo difícil nos pone frente a nuestra dificultad de decir y de escribir. En el contexto académico, la escritura ha sido el soporte más frecuente para la exposición de las ideas, interpretaciones y tesis de la historia, también de la historia de la educación. Como una suerte de poso intocable, algunas obras han ido adoptando el rango de obras de referencia y, con ellas, las ideas que sostienen. Aun siendo variables en los momentos, estas referencias condicionan lo que vemos, lo que leemos, lo que escuchamos. Necesitamos las voces y las visiones, pero ¿cómo hacer para que no nos encapsulen?

$\mathrm{Si}$ analizamos la serie de documentales que el Noticiario Español y la productora NO$\mathrm{DO}^{3}$ emitieron sobre la infancia durante la II Guerra Mundial, percibimos de la serie que 
aquello que se cuenta es la historia de una infancia feliz, ajena a la guerra y a las agresiones del totalitarismo. Niños alemanes, ingleses, franceses, belgas, etc. son representados comiendo, aprendiendo, haciendo deporte y jugando. Para abstraerse de esta falsa imagen debe de darse importancia a las breves locuciones que aparecen indicando que están hablando de niños refugiados, repatriados, reacomodados o adoptados. Pero ¿como ir más allá desde la serie?

Hay quienes piensan que la única vía para dar un paso más en el conocimiento acerca de la historia de la educación es la de acudir a fuentes hasta el momento inexploradas. Esta propuesta pasa tanto para dar legitimidad a las que recientemente pueden haberse abierto camino en nuevos proyectos de investigación (documentos audiovisuales, por ejemplo) como por ensayar nuevas posibilidades. Vemos una muestra de ello en la incorporación de nuevas fuentes en las revistas del área. Los 631 artículos dedicados a la cuestión metodológica en la Paedagogica Historica son buena muestra de ello, como también lo es la incorporación de espacios dedicados a las fuentes.

Sin menospreciar estas opciones -que sin duda pueden aportar nuevos datos para enriquecer lo que ya se sabe- observamos aun así una confusión entre la relación directa que establecen entre la diversidad de fuentes y la mejora en el conocimiento histórico. Y a nuestro modo de ver, esto no es así. No lo es porque tener acceso a más datos no siempre se traduce en un conocimiento mejor y más crítico de lo estudiado. Recordemos: los datos se someten a interpretación, y si esa sigue siendo la mayoritaria y la legitimada a lo largo de los tiempos los nuevos datos no son nada más que nueva argamasa para armar mejor el discurso monolítico. En consecuencia, el foco no se encuentra tanto en la diversidad de fuentes como en la manera en la que nos aproximamos a ellas y en qué lógicas de análisis las sometemos. Ahí es cuando entra en juego las perspectivas de quien investiga, su concepción epistemológica, su capacidad de suspender prejuicios, su valentía de poner (se) en cuestión a sí y a sus hipótesis. Requiere, en definitiva, tomar la decisión sobre el lugar en el que se va a colocar para llevar a cabo su trabajo de búsqueda. Al fin y al cabo, como nos decía Le Guin, en todo plano hay un reverso:

Había un muro. No parecía importante. Era de rocas bastas unidas de cualquier manera con mortero. No era más alto que un adulto; hasta un niño podría escalarlo. Cuando se cruzaba con una carretera, en lugar de tener una puerta, degeneraba en pura geometría, en una línea, en una idea de frontera. Pero la idea era real. Era importante. Durante siete generaciones lo más importante del mundo había sido aquel muro.

Como todos los muros, era ambiguo, tenía dos caras. Lo que estaba dentro y lo que estaba fuera dependía del lado en el que estuvieras. (Le Guin: 2020, p.28).

Esta observación relativa a la posición que se toma para adentrarse en la investigación nos remite a la pregunta por las estructuras y series que desde la investigación se han construido o han venido dadas. La pregunta por las memorias que subyacen en los elementos (documentos, fotografías, dibujos, reportajes...) de las series remite a las vivencias que 
narran. Solamente con esta imbricación es posible escapar de una imaginería conformada. Nombrar y pensar lo difícil en educación a través de la escritura demanda el ensayo como narrativa, como una forma de aproximarse que asume la duda y el vacío como principio y posibilidad de fin. Son las dudas iniciales las que impulsan el pensar en movimiento. Un pensar que no se recoge a si mismo en los espacios de comodidad de querer volver a investigar y decir aquello que ya se sabe, sino que exige problematizar la realidad siendo conscientes de la trampa de lo obvio, eso es, sabiendo que no estamos inmunes a la incorporación de una costumbre de pensamiento que nos presenta aspectos de la realidad investigada como aspectos obvios cuando no lo son en absoluto. Recorrer a una mirada externa, de alguien que no forma parte de la misma cultura y formación, para que vuelva a observar y decirse por las fotografías y otras fuentes documentales, como se realiza en los workshops dirigidos por Grosvenor, es una práctica que permite abrir la mirada que podría quedarse encerrada en sí misma y salir al encuentro de otras distintas, las que a menudo detectan elementos singulares que han pasado inadvertidos por el equipo de investigación. El punto de fuga que abren las nuevas apreciaciones conlleva de nuevo a dudar de lo pensado, de la hipótesis de partida, y la certidumbre de estar en el buen camino se tambalea. También pueden buscarse distintas posibilidades interpretativas a aquello que se ve, lee o escucha. A modo de juego racional, empezar a dudar del saber de uno mismo, sin por ello paralizarlo, nos ubica en un investigar que es aprendizaje en movimiento. Un aprendizaje que, continuo, no acaba cuando se termina la investigación, sino que es la misma la que abre nuevos interrogantes. Por ello decimos que las dudas tienen que formar parte de los escritos de investigación. El acto de formularlas es compartir lo frágil, es ponerse en condición de explorar. Quizás el ensayo escrito en clave poética es una opción, Berger escribía que

Los poemas no se parecen a los cuentos, ni tan siquiera cuando son narrativos. Todos los cuentos tratan de batallas, de un tipo o de otro, que terminan en victoria y derrota. Todo avanza hacia el final, cuando habremos de enterarnos del desenlace.

Indiferentes al desenlace, los poemas cruzan los campos de batalla, socorriendo al herido, escuchando los monólogos delirantes del triunfo y del espanto. Procuran un tipo de paz. No por la hipnosis o la confianza fácil, sino por el reconocimiento y la promesa de que lo que se ha experimentado no puede desaparecer como si nunca hubiera existido. Y, sin embargo, la promesa no es la de un monumento. (¿Quién quiere monumentos en el campo de batalla?) La promesa es que el lenguaje ha reconocido, ha dado cobijo, a la experiencia que lo necesitaba, que lo pedía a gritos. (Berger, 1986, p.21-22).

La promesa en la investigación, podemos pensar, es el movimiento de una misma; en los escritos de investigación es el movimiento compartido con los lectores. Investigaciones y escritos escurren así la figura del "poeta fingidor" - como el del poema de Fernando Pessoa que Toti Soler musicó en 2013- y del "poeta labrador" -poetizado por Jacint Verdaguer y cantado por Jaume Arnella en 2002- para devenir un "poeta de la duda". 
Por ello decimos que para acoger lo difícil, los textos conclusivos, pensados ya inicialmente como informes de un proceso de investigación que consiste en transferir unos conocimientos aceptados, en aplicar un método ya preestablecido o una herramienta ya contrastada, no sirven. Estos refuerzan el estatus académico, pero no impulsan el pensar aquello intolerable, invisible, oculto o silenciado, no son promesas de tierras desconocidas. Es decir, cuando el proceso de aprendizaje del haber pensado en movimiento adquiere la forma escrita, mostrar cómo se ensaya es, más que oportuno, necesario. La pregunta concreta inicial, tan anhelada en los procesos metodológicos clásicos, cierra la investigación y la lectura. Sabemos que el equilibrio entre presentar las rutas de investigación, mostrar las derivaciones que ha tomado la investigación y enseñar las dudas que se abren con la lógica académica y de financiación de las investigaciones es complicado. Pero sin ello, la investigación, más que exploración se convierte en conformación de un saber ya aceptado. Es necesario evitar la escena descrita por Manguel:

Cómo ocurrió todo ello está minuciosamente detallado en este libro, en la vida diaria de unas cuantas personas corrientes, rastreada aquí y allá en memorias familiares, historias de ciudades y descripciones de la vida en lugares distantes y hace mucho tiempo. Pero siempre se habla en él de individuos, nunca de nacionalidades ni de generaciones cuyas elecciones no pertenecen a la historia de la lectura sino a la de la estadística. Rilke preguntó en una ocasión: “¿Es posible que la historia entera del mundo haya sido malentendida? ¿Es posible que el pasado sea falso, puesto que siempre hemos hablado de masas, como si estuviéramos hablando de una reunión de personas, en lugar de hablar de la persona en torno a la cual se habían congregado las demás, porque era un desconocido y se estaba muriendo? Sí, es posible”. (Manguel, 2012, p.504).

El proyecto de investigación sobre la colección de dibujos realizados durante la guerra civil española (1936-1939) en un marco escolar terminó con una conferencia en el Centro Cultural el "Born" de Barcelona (2019) 4 . Durante el turno de preguntas posterior, una persona mayor, una abuela, pidió la palabra. Explicó que ella era del barrio, Sants, vivía en un entorno cercano al centro educativo, un centro público de inspiración republicana que, conjuntamente con otra escuela, esta de signo anarquista, daban cobertura colegial a las clases medias del barrio. La neutralidad, la inclusión y la equidad formaban parte de los principios de esta escuela, dirigida por Pere Blasi, geógrafo, miembro de ERC -Esquerra Republicana de Catalunya (Izquierda Republicana de Cataluña), que defendió la neutralidad escolar cuando se aprobó el Consejo de la Escuela Nueva Unificada -programa que actuó como normativa(Padrós et al, 2015, p.483). Por los análisis efectuados, centrados tanto en la psicología del dibujo como en los contenidos expuestos, habíamos construido una narración de cómo era vivir en este estado de violencia, como era la cotidianidad de una escuela que anhelaba poder ofrecer un "oasis de paz" -como se le llamó en su momento- a los niños y niñas. Un ambiente que fue dibujado por ellos, especialmente en la serie "patio". Un ambiente que, por entrevistas (Padrós, tesis en curso) sabemos que marcó la experiencia escolar de estos niños y niñas. Pero lo que sorprendió fue que los dibujos expuestos en el transcurso de la 
conferencia habían evocado a esta persona la profunda celosía que le inspiraban los niños y niñas del colegio. Ella no había podido acceder al sistema. Como ella, tantos otros y otras. La serie con la que habíamos trabajo nos adentró a atender otras experiencias de las habitualmente narradas, habían aportado complejidad, pero no contemplaba el silencio de los niños y niñas olvidados, bien fuera por cuestiones económicas o por decisiones de la familia. Lo difícil sobrepasa la posibilidad de estar en cajitas de ordenación, como suponen los modelos de acercase a un fenómeno, evento o serie de manera analítica. Porque lo difícil no soporta la necesidad investigadora de ser concreto, aunque sí de precisión que, en este caso, es opuesto a la contención. Atender a este silencio, el de la exclusión, no era posible desde la serie. Tampoco desde la documentación del colegio. Se requería acceder a lo que existe detrás de los muros escolares pero ya no como contexto, sino como parte integrante del texto. Lo difícil es hallar su lugar apropiado, huyendo de lo llano, de lo que sobresale; alejándose de lo que mueve una compasión estéril.

Los nombres grabados, cual grafiti infantil, en los adoquines de la entrada por los niños y niñas de la antigua escuela de Pallarols, son parte también de la historia escolar, en esta ocasión de un centro rural. De hecho, son uno de los testimonios visuales más vivos que persisten hoy, cuando el centro ya ha desaparecido y en la población no existen niños y niñas que puedan acudir a este centro, fruto del despoblamiento de los Pirineos. La escriturarealizada sobre piedra en el margen de la escuela, en esta ocasión con trazos infantiles, nos coloca hoy, como visitantes al pasado, en el umbral de su historia. En un margen.

Pero los márgenes no son siempre nítidos. En ellos hay líneas discontinuas y líneas porosas. Es un lugar de indefinición, borroso, que no se deja captar diáfanamente. Los márgenes no son límites establecidos, sino una suerte de frontera que se mueve junto con lo que se sabe de su centro. Y de lo que no se sabe. A menudo los márgenes redibujan el centro. Obligan a reacomodar vectores causales, a corregir calificativos, a retirar actores protagonistas. Cuando prensamos una bolsa de plástico llena de líquido, este se reparte. La diferencia es que en historia el líquido no solo se reparte, sino que puede transformarse en otra sustancia.

Tal vez sea lo que nos dice lo que le pasó a Lluís: por haber ido al colegio durante el franquismo, se le suponían unos determinados recuerdos escolares. No obstante, él no se encontraba en el centro del discurso, sino en uno de sus diferentes márgenes. Fue a una escuela renovada, lo cual no niega en absoluto la existencia de una línea pedagógica extensamente aplicada a lo largo de la geografía del estado español, la que en realidad era la dominante. Pero sí señala que "la bolsa de plástico" tenía poros, y podemos acceder a ellos si escuchamos no solo las leyes de educación, sino también los que en aquellos tiempos eran alumnos, pues pueden romper la homogeneidad de recuerdos que se piensan que tienen. $\mathrm{O}$, incluso, que se les pide que tengan. Si se percibe que se penaliza la disensión que rompe el pretendido consenso del que hablábamos antes, muchos relatos quedan por decir y ya no pueden aparecer cuando quien vivió tal o cual experiencia muere.

El peligro que las voces discordantes perciben a ser penalizadas no sólo es sentido por los testimonios de los hechos, sino que también puede ser percibido por algunas de las 
personas que quieren escribir las historias de los márgenes. Escribir la historia de la educación, en efecto, no debería censurar vocablos, lógicas ni estructuras de relato diferentes a los mayoritarios. Y casi nos atreveríamos a decir que no las censura. Porque si observamos a nuestro alrededor, hay iniciativas que muestran que tal vez el miedo a la censura era en realidad una autocensura, un imaginario de las jerarquías del saber que les paralizaba a la hora de actuar. Cuando se han -o nos hemos- autorizado a adentrarnos en un trabajo pensado desde otra óptica, se ha evidenciado la inmensidad de posibilidades que ofrece. Tal vez, aquello que se requiere es abordar otras series, incómodas, difíciles, pero que de manera insistente hagan desplazar el centro de la investigación, aunque ello contradiga los parámetros de la investigación académica reconocida. Lo difícil, por necesitar ser presentado con otras rutas y otras posibilidades, huye del texto hegemónico desde el que se fabricado el consenso. Dicho de otra manera, en un marco definido bajo lo calificable como "académico" es difícil atreverse a abrir dudas y a cuestionar explicaciones de los hechos históricos no solo por los elementos externos a quien investiga sino también por su propio imaginario y saber adquirido hasta el momento. $\mathrm{Y}$ es que, en realidad, quién investiga en las instituciones universitarias forma parte de ellas y es a la vez configurado y conformador de éstas. Difícil es lo complejo, difícil es lo feo, difícil es lo poco soportable, difícil es lo inverosímil, difícil es lo que nos es extraño, pero también aquello que hemos naturalizado hasta tal punto que ya no vemos o ya no sabemos contar.

Mi madre continuó esa labor al escribir la historia de un sobreviviente de la frontera, el nativo de California Ishi. Admiro su libro de un modo tan profundo como a quien lo inspiró, pero nunca me ha gustado el subtítulo: "una biografía del último indio salvaje de Norteamérica", pues contradice el sentido y el espíritu de la historia. Ishi no era un salvaje. No provenía de tierras salvajes, sino de una cultura y una tradición de raíces mucho más profundas y bases mucho más sólidas que las de los colonos que masacraron a su gente para quitarle la tierra. No vivía en tierras salvajes, sino en un mundo querido y familiar que él y los suyos conocían colina por colina, río por río, piedra por piedra. ¿Quién convirtió esas colinas doradas en una salvajada de sangre y pena e ignorancia? Si hay fronteras entre la civilización y la barbarie, entre el sentido y el sinsentido, no son líneas trazadas en un mapa ni regiones de la tierra. Solo son fronteras de la mente. (Le Guin: 2018, pág. 59).

Hoy en día, la crítica que la escritora hace acerca al vocabulario utilizado por su madre es fácil de compartir. Lo interesante es lo que pone de relieve. Es posible pensar que si una mujer sensible y culta como su madre presentó el nativo como lo hizo sin ningún reparo fue precisamente por un vocabulario institucionalizado y perpetuado dentro de su disciplina académica. El léxico forma parte del acervo cultural, de manera que si no prestamos atención a las palabras con las que narramos puede que el relato sea una muestra de la contradicción existente entre lo que hemos pretendido narrar y la forma con la que lo hemos hecho. Puede que eso explique por qué cuando hemos escrito a partir de investigar con imágenes hemos necesitado de un lenguaje más literario. Así pues, nos vimos con la necesidad de introducir 
el decir plástico camuflándolo dentro de un registro académico para que nos fuera posible comunicar lo inasible de los documentos audiovisuales y artísticos.

Éste último es uno de los motivos por los que decimos que lo difícil es trabajar con aquello que hemos naturalizado y que por lo tanto ya no sabemos ver ni distinguir. Por eso decimos que lo difícil es sobrepasar la posibilidad de colocar los hechos históricos en cajitas ordenadas linealmente. Por eso pensamos que lo difícil exige salir de los cauces marcados por el acervo historiográfico y encontrar un lugar que combine la rigurosidad con la libertad de pensamiento. Lo difícil es romper con las estructuras -individuales y sociales- que funcionan como andamiajes intocables por los que seguir avanzando en el conocimiento de la historia. Porque contar lo difícil es abrir la puerta a la diversidad de voces, de percepciones, de interpretaciones. Contar lo difícil demanda salir de la historia monolítica en singular y enmarañarse en una red de historias abiertas en plural. De ahí que percibimos que cuando la referencia no impulsa sino ofusca es cuando se requieren otras voces insistentes.

\section{Más que escuchar en los márgenes, recolocarse en los mismos}

¿Cómo aproximarse? ¿A qué prestar atención? ¿Hacia dónde dirigir la mirada? Como explican de la geóloga de la novela, una dirección interesante es dirigirse a los márgenes: "Le gustan los márgenes por lo que contienen en medio. Los márgenes por lo que delimitan. Para empezar, trabajó los contornos, como cuando repasaba en negro el trazado de sus dibujos, luego se preocupó del centro" (Filhol, 2020, p.56). Una vía sería, entonces, seguir escuchando las mismas fuentes, seguir visualizando los mismos documentales, pero ahora hacerlo prestando atención a sus márgenes: ¿quién los guionó? ¿Quién asumió el gasto de producción? ¿Quién diseñó? ¿Quién maquetó? ¿Quién lo visualizó y cómo lo recibió?

Para romper o escapar de los tópicos y de los discursos integrados es importante que nos dotemos de elementos de ayuda, de fundamentos epistemológicos que funcionen como faros, de rutas de investigación que nos protejan de las repeticiones de discursos pedagógicos e históricos construidos des de premisas simplistas, oficialistas o reduccionistas como lo pueden ser los generados por corrientes populistas.

Si analizamos los informativos que transmitieron los Noticiarios y Documentales (NODO) durante el período de 1942 y 1975 sobre las enfermedades epidémicas que estaban en la población y que afectaban a la educación por la creación de centros específicos, por su incidencia social y en especial, sobre la infancia y la juventud y por la celebración de los pocos éxitos logrados- eran censurados sistemáticamente, como sistemáticamente se censuró la pobreza de la población, el analfabetismo contundente o las manifestaciones y movimientos contrarios al régimen. Ciertamente, en su momento, escapar de la censura no era tarea fácil, menos lo era cuando en líneas generales se aceptaba formar parte del aparato propagandístico y de modelación del régimen, pero, aun así, se quería noticiar alguna información que requería reportar parte de lo previamente censurado. El NO-DO de 1949 sobre la visita a un centro antituberculoso, en medio de la negación del alcance de la enfermedad $^{5}$; la visita a la Ciudad de lo Muchachos, en un estado que, siguiendo sus cánticos, 
los muchachos no tenían problemas y eran disciplinados ${ }^{6}$ o, como señala Viñao (2020), repasar los desatinos de la Ley de Primaria de 1945 como argumento a favor de la aprobación de la Ley General de Educación de 1970, era una tarea que requería un doble juego de negación y negación de la negación, similar al que los diplomáticos portugueses realizaban cuando existían visitas oficiales de Franco a Portugal (Paz, 2020). Cuando el tópico eran las enfermedades epidémicas, ello aumentaba la problemática: si querían afrontarse, se debía informar a la población, pero por principio era mejor el silencio, ¿cómo atacar entonces a la situación? Desde la historia de la educación podemos resolver esta complejidad listando los silencios provocados por la propaganda franquista, pero ello no es suficiente para construir una narración.

Los fundamentos epistemológicos deben ir acompañados de unas prácticas metodológicas acordes con lo que ellos plantean. Una concepción problematizada no puede exponerse con relatos articulados con palabras que cierran en lugar de abrir posibilidades. La interpretación no tiene por qué ser ambigua, pero la forma de presentarla debe enseñar des de qué elementos hemos partido para llegar a ella y qué decisiones hemos ido tomando hasta llegar a su formulación. Sin dejar de lado la precisión en el discurso histórico que se expone, la escritura de lo que se quiere compartir tiene que ser lo suficiente sensible y humilde para no comunicar las ideas como algo cerrado, situado totalmente en la Verdad ni convertirse en elemento excluyente de otras opciones posibles.

En una experiencia de investigación acción reciente, los estudiantes de educación social pintaron un muro -un grafiti- en una de las zonas de paso de Vic recordando las características del indoctrinar franquista ${ }^{7}$. Tras un proceso de investigación de la represión franquista en los centros educativos, y mediados por la ayuda de un pintor de calle -Roc Blackblock-, empezaron su composición. El muro iba adquiriendo color, aunque de manera más o menos discontinua, la monocromía dominaba, de la misma manera que dominó un determinado período de la historia. Sin embargo, en medio del proceso, algunas de las personas que circulaban preguntaban qué sucedía. Pero aquello que no quedó registrado, ni en las memorias ni en los registros fotográficos, fue lo no esperado, la demanda de una persona mayor para que se respetara un espacio en blanco como homenaje a un muerto familiar. Esta era una historia desligada del proceso de investigación, refería a un episodio reciente, pero hoy vemos que estaba vinculada a los orígenes epistemológicos de la actividad: la ocupación de la calle como acto de ciudadanía. Nos preguntamos ahora, ¿por qué no la anotamos? Pues era, fundamentalmente, uno de las interrupciones que permitían cortar con la monocromía.

Los diarios de las investigadoras recopilaron quizás esas dudas nacidas en los márgenes, los informes de proceso no, las presentaciones en congresos de la actividad tampoco. Es pertinente aquí recuperar la sensación de malestar de una profesora en el marco de las XXIV Jornades d'història de l'educació: “L'impacte de les reformes educatives durant l'etapa democràtica (1975-2006)", cuando habiéndose presentado diferentes propuestas de educación universitaria en el área de historia de la educación, percibió que sólo se mostraban los "éxitos" avalados por la comunidad. Es evidente que no habíamos respetado el principio citado de más que escuchar en los márgenes, recolocarse en los mismos. 


\section{Narrativas que ensayan, no consuelan, no determinan, no refuerzan, pero sí interpelan}

Para abrir la posibilidad de moverse entre lo difícil sin caer en una angustia paralizante es importante generar espacios que hagan posible la duda, el error, el ensayo, la pregunta. Es importante pensar en un contexto sostenido por la confianza para, así, poder intercambiar ideas, hipótesis, valoraciones, interpretaciones. Los seminarios bien podrían responder a estos espacios a los que nos estamos refiriendo.

Lo difícil demanda una palabra que es parte de la metodología del pensar, su espacio es el del seminario que no requiere un acto concluyente ni el dar cuenta de los recorridos del pensamiento. Los seminarios serían aquellos espacios que, recuperando la idea que subyace a los dirigidos por el profesor Jorge D'O Ramos, son descritos como aquel lugar

donde germinan y crecen las plantas (semillero). De ahí que no nos puede extrañar que el seminario ha representado históricamente un espacio que intenta regar todas las ideas compartidas para que puedan crecer más allá de la experiencia lectora acaecida previamente e individualmente $\mathrm{y}$, por consiguiente, relacionarse con diferentes autores y textos de nuestra disciplina que permite poner las bases para generar, a la larga, una producción de discurso más creativo y subjetivo (García, Gómez, en prensa, s/p.).

Se contempla en los mismos la posibilidad de tener un texto como punto de arranque, pero es a partir de la discusión crítica con el mismo, con sus fuentes orales, visuales, reportajes y documentales que el discurso va adquiriendo nuevas formas, de momento, sólo esbozadas. Se vuelve atrevido, e incluso a veces insolente. Se ha desatado el pensar, condición de base del poder saber lo difícil en educación. Porqué "lo atado y bien atado" no funciona en educación. Tampoco en historia de la educación. Y ello solo es posible desde el hablar. Es decir, atender a lo difícil demanda de unos seminarios que piden ayuda de la conversación. Pues en la misma, como recogía en ocasión del artículo "Les converses: elements per a la història cultural":

Pensar es este punto donde aparece de manera más lúcida la íntima relación de la historia cultural y la práctica de la conversación. No solo por ser un elemento de estudio, la conversación interesa a quien relata la historia cultural, sino también por ser ella uno de los caminos que permite alimentar el relato. Así es, la conversación forma parte de la experiencia investigadora; de ella nos ayudamos para adentrarnos y estirar del interrogante que interpela nuestra curiosidad porqué tiene la potencia de trasladar a los interlocutores que le dan vida a un punto que los alejan de los contornos del saber, del podemos decir. El tránsito de la conversación desplaza a partir de la pregunta, del apunte lanzado por oro a partir de un acontecimiento inesperado que cuestiona el conocimiento de la realidad disponible hasta el momento; y conduce a "tocar" aquello desconocido, inédito o impensable hasta el momento. (Gómez, 2013, p.56) 
Colectar estos esbozos de insolencia es tarea de la escritura que emerge de los seminarios sin obligarse a reducirlos, pero dándoles forma leíble para quién no estuvo en el seminario es uno de los retos que emergen. ¿Cómo reconvertir la palabra dicha con palabra escrita, la palabra escuchada con palabra relatada? La escritura torcida construida en los márgenes es quizás una opción para narrar interrupciones, huellas gráficas, seminarios repletos de conversaciones que sólo acontecen en los espacios, prácticas y escrituras de la dificultad.

Otra dificultad se encuentra en cómo contar la historia, pues el contexto de escritura y de recepción de ella es un contexto fuertemente institucionalizado, sobrenormativizado y altamente competitivo. A la dificultad de qué contar se le añade el cómo contarlo. El cómo no solamente atañe al vocabulario utilizado en la escritura, sino también al tono y al estilo de lo escrito y a las fuentes a las que referirse y apoyarse durante el proceso de interpretación de las situaciones estudiadas.

Si no se quiere repetir lo ya dicho sin volverlo a revisar, escribir la historia de la educación es difícil porque el discurso legitimado ha ido sepultando las vías de acceso al momento de tiempo que quiere conocerse mejor, más ampliamente, desde otras perspectivas de las que ya se dispone. El número de capas bajo las que se mantienen las fuentes, las versiones, las recepciones de los hechos y situaciones es variable según la época en las que se dieron, según el ámbito en el que fueron protagonistas, según los actores que participaron en ellas y según el valor o la importancia que se le da en los tiempos presentes. Pues no todo lo presente es actual ni toda actualidad recibe la misma atención.

Hay muchas narrativas con las que ayudarse a contar la historia sin cerrarla. Lenguajes artísticos acercan la perspectiva poliédrica del relato de la historia a quienes se acercan a ella, y así es como los invita a abrazarla sin reproducir tópicos ni imponer visiones incuestionables. El trabajo con las narrativas plurales ofrece la posibilidad de mostrar el proceso de ensayo que se vive mientras vamos aproximándonos a lo que se quiere comprender. Así, la escritura va enseñando el camino que se ha ido recorriendo con todas las vicisitudes que se encontraron, eso es, sus altos en el camino, los atajos que se descartaron, las rutas por las que se optó y los cruces donde se han tenido que tomar decisiones, qué decisiones se tomaron y por qué.

Dando testimonio del trayecto es cómo se puede poner de manifiesto hasta qué punto la duda, el desconcierto, el vacío, pero también aquella actitud intuitiva, persistente y confiada forman parte de la experiencia de conocer, comprender y escribir la historia. Sin que ello implique lo difícil se vea superado, empequeñecido, por las políticas del texto del ámbito académico, aunque las retóricas difíciles ocultan a veces esa ineptitud por comprender y escribir lo difícil. "Escribe difícil y parecerá verdadero" sería el lema equivalente a hacer justo lo contrario que demanda atender y escribir lo difícil. De hecho, lo difícil se ve superado, empequeñecido, por las políticas del texto del ámbito académico, aunque las retóricas difíciles ocultan a veces esa ineptitud por comprender y escribir lo difícil.

Porque lo difícil requiere suspenderse en lo incomprensible. Comprender lo difícil pide ponerse en manos de una narrativa más intuitiva, más sensible, incluso diríamos que más poética. Moverse entre lo difícil pide, aunque parezca paradójico, aflojar tensiones, 
despojarse de rigideces para entrar en un estado grávido lo suficientemente flexible para poder ir acogiendo aquello imprevisto, (casi) impensable, controvertido e inquietante que puede aparecer a lo largo del proceso. En definitiva, comprender y escribir lo difícil de la educación nos hace plantear que para evitar lo común, lo ya sabido y expuesto, lo repetitivo, son necesarias las narrativas que ensayan, no consuelan, no determinan, no refuerzan, pero si interpelan.

\section{Notas}

1. La audición publica tuvo lugar el 11 de marzo de 2020. La demanda tuvo origen en el proyecto desarrollado con la ayuda de la Fundación Puig-Porret (OR432FPP1120) para realizar el proyecto «La represión franquista en Vic desde instituciones educativas» y se vinculó a las actividades del proyecto ARAEF: Análisis de las representaciones audiovisuales de la educación en documentales y noticiarios durante el franquismo. Programa Estatal de Investigación, Desarrollo e Innovación Orientada a los Retos de la Sociedad, en el marco del Plan Estatal de Investigación Científica y Técnica y de Innovación 2013-2016, (Ref. EDU2017-89646-R, AEI/FEDER, UE).

2. Indicar que en los dos volúmenes de fotografías editados sobre la población no aparecen (Basagaña: 2001; Valls: 1992) a pesar de contar con más de 1250 fotografías no de los libros-álbumes contiene 975 imágenes extraídas mayoritariamente del Archivo Municipal. 85 son dedicadas a la educación 52 a las 2 escuelas religiosas, 9 a las escuelas nacionales ( 3 del período de la II República, 6 del franquismo), 2 a la escuela racionalista, 4 a la escuela Gracia, 13 a la Academia Casals, sólo sección primaria y adultos y 5 al parvulario municipal y 5 de alumnos como asistentes a actos públicos.

3. El noticiario NO-DO (Noticiarios y Documentales) fue el principal aparato propagandístico del Estado franquista). Se reguló por una orden de 17 de diciembre de 1942 y dependía de la Vicesecretaría de Educación Popular (BOE, núm. 356, de 22 de diciembre), según estipulaba el decreto de 10 de octubre de 1941 por el que se organizaban los servicios de la Vicesecretaría de Educación Popular de FET y de las JONS, publicado el 15 de octubre de 1941.

4. DiDD. Documentación y difusión digital del patrimonio educativo producido entre 1936-1939 en las escuelas de Barcelona. Los dibujos de la infancia sobre la vida cotidiana en tiempos de guerra", Plan Nacional de I+D+I 2011-2013 (Ref. EDU2010-20280).

5. NO-DO, n.352A. «Franco en Galicia. Visita el sanatorio antituberculoso del Pinor, en Orense», 3 de octubre de 1949. 10:33; 07:17-08:20. Disponible en línea en <http://www. rtve.es/filmoteca/no-do/not352/1468166/ [última consulta 21 de octubre de 2020].

6. NO-DO, n.364A. «El ministro de Educación Nacional visita la Ciudad de los Muchachos», 26 de diciembre de 1949. 09:54; 03:03-04:32. Disponible en línea en http://www.rtve. es/filmoteca/no-do/not-364/1468082/) [última consulta 21 de octubre de 2020].

7. Proyecto dirigido por Núria Padrós desarrollado con la ayuda de la Fundació Puig-Porret (codi: OR432FPP1120) y vinculado a las actividades del proyocto ARAEF: ARAEF. Análisis de las representaciones audiovisuales de la educación en documentales y noticiarios durante el franquismo. Programa Estatal de Investigación, Desarrollo e Innovación Orientada a los Retos de la Sociedad, en el marco del Plan Estatal de Investigación Científica y Técnica y de Innovación 2013-2016, (Ref. EDU201789646-R, AEI/FEDER, UE). 


\section{Referências}

BASAGAÑA, M.M. L’Abans. Manlleu. Recull Gràfic 1886-1965. El Papiol: Efadós, 2001.

BERGER, J. Y nuestros rostros, mi vida, breves como fotos. Madrid: Hemann Blume, 1986.

BERNAL, M. "La representación de la educación infantil en el periodo 1943-1975" en COLLELLDEMONT, E.; VILANOU, C. (coord.) Totalitarismos europeos, propaganda y educación. Una historia visual desde los NO-DOS. Gijón: Trea ed., 2020. c.3. p. 39-58.

BURKE, P. ¿Qué es la historia cultural?. Barcelona: Paidós, 2006.

CASAS, P. i CROSAS, C. Nouvinguts a la ciutat: La construcció urbana de Manlleu, 1900-2005. Vic: Eumo, 2007.

COllelldemONT, E.; PADRÓS, N.; CERCÓS, R. "Images That Portray, Challenge, and Refuse: Visual Content and Education in Francoist Spain, 1939-1975" en ECCER, 2019. Hamburg.

RAMOS DO Ó, J. Fazer a mão. Por uma escrita inventiva na universidade. Lisboa: Edições do Saguão, 2019.

FILHOL, É. Doggerland. Barcelona: Anagrama, 2020.

GARCÍA, J.; GÓMEZ, A. "La pervivencia del sentido de los seminarios en contextos universitarios actuales" en VVAA. Filosofia e Educação: Escola, Violência e Ética. Curitiva: Appris Editora, (en prensa).

GÓMEZ, A. "Les converses: elements per a la història cultural" Temps d'Educació, 44, Universitat de Barcelona, 2013, p. 49-61.

OSA, D. De l'escola unitària dels nens fins al Puig-Agut. Trabajo de grado. Instituto de Manlleu. 2006-2007.

LE GUIN, U; NAIMON, D. Conversaciones sobre la escritura. Barcelona: Alpha Decay, 2020.

LE GUIN, U. Contar es escuchar. Barcelona: Círculo de Tiza, 2018.

MANGUEL, A. Una historia de la lectura. Madrid: Alianza, 2012.

PADRÓS, N., et al. "The Spanish Civil War as seen through children's drawings of the time" Paedagogica Historica , 51, n.4, 2015.

PADRÓS, N. Aprender psicología a través de los dibujos. La experiencia a través de los fondos del "Grup Escolar LLuís Vives. Tesis en curso. Universidad de Vic. En curso.

PAZ, A.; CEREJO, P. "La imagen de Franco como otro en el Jornal Portuguès (1938-1952): relaciones ambiguas de propaganda en la gran pantalla" in COLLELLDEMONT, E.; VILANOU, C. (coord.) Totalitarismos europeos, propaganda y educación. Una historia visual desde los NO-DOS. Gijón: Trea ed., 2020. c.11. p. 243-260.

ZWEIG, S. Encuentros con libros. Barcelona: Alcantilado, 2020.

VALLS, X. Manlleu, 110 anys de fotografía. Manlleu: Gràfiques Manlleu, 1992

VIÑAO, A. "La educación escolar" in COLLELLDEMONT, E.; VILANOU, C. (coord.) Totalitarismos europeos, propaganda y educación. Una historia visual desde los NO-DOS. Gijón: Trea ed., 2020. c.2. p. 59-80.

\section{Correspondência}

Eulàlia Collelldemont Pujadas: Es profesora titular del Departamento de Pedagogía de la Universidad de Vic, Universidad Central de Catalunya y directora del MUVIP (Museu Pedagógico Virtual). Se ha especializado en las bases teóricas e históricas de la pedagogía estética y en el análisis de las 
representaciones audiovisuales en la historia de la educación contemporánea, así como en la historia de los centros de memoria y estudios sobre la memoria educativa. Ha liderado diferentes proyectos de investigación histórica financiados por el Ministerio de Ciencia, Innovación y Universidades y ha participado en proyectos internacionales y nacionales, además de publicar libros y revistas sobre teoría e historia de la educación y museos pedagógicosfonte.

E-mail: eulalia@uvic.cat

Anna Gómez Mundó: És doctora en Pedagogía. Profesora agregada del Departamento de Pedagogía de la Universitat de Vic-Universitat Central de Catalunya. Investigadora del Grupo de investigación de Educación de la Universitat de Vic (GREUV). Coordinadora de Educación Social. Sus líneas de investigación son la relación educativa y la narrativa en la educación, ámbito des del que ha participado en diferentes investigaciones.

E-mail: anna.gomez@uvic.cat

Texto publicado em Currículo sem Fronteiras com autorização dos autores. 